\title{
Fabrication of Hybrid Electro Mechanical Tricycle with Regenerative Braking System
}

\author{
Abhinay Nigam ${ }^{* 1}$, Prof. Suman Sharma ${ }^{* 2}$ \\ ${ }^{*}$ PG Student, Automobile Engineering, Sagar Institute of Research and Technology, Indore, M.P., India \\ $*^{2}$ Head, Mechanical Engineering Department, Sagar Institute of Research and Technology, Indore, M.P., India
}

\begin{abstract}
Hybrid EMT is a Human controlled Vehicle that uses both human vitality and electric vitality to drive the vehicle. The key destinations behind this examination is to produce a fitting strategy for transportation which would utilize human imperativeness in a viable way to deal with be used for driving the vehicle, for example, it runs quicker than the present day human controlled vehicles. Consequently the human quality like quality and deficiency (shortcoming) Hybrid EMT shifts from most other choice imperativeness vehicles, is the rider gives pedal power, which power is extended estimated 1.8 times terms in Gear proportion by the EMT drive course of action. In the event that a man is feeling exertive by pedal exertion so electric drive is accessible at the driver wheel, DC motor is connected at the back side, which run a vehicle by method for battery with economic speed rate.
\end{abstract}

Keywords: Hybrid EMT, Human controlled vehicle, DC Motor, frame, suspension, steering, braking etc

\section{Introduction}

To outline a mixture EMT which gives the rider perfect way of comfort for riding over long separations without utilization of unit fuel besides recalling the pace is around like the expedient vehicle. These new cycles can have all the convenience which essential with all the clear economy of customary cycles. Electromechanical Tricycle with Regenerative Braking System is a three wheeled, totally encased, fairing, complete with roll restrict, suspension, seat straps and vitality sparing framework. Where the Hybrid EMT changes from most other alternative essential vehicles, is the rider gives pedal power, which power is extended around 1.8 times by the EMT drive arrangement.EMT runs quicker than other cycle by method for pedal alone however If a man is getting depleted by pedal exertion so electric drive is accessible at the driver wheel, centre point motor is joined at the back side, which run a vehicle by method for battery with financial pace rate. Battery is accused of the transformation of mechanical vitality into electrical vitality with of regenerative stopping mechanism when leverage will apply. There are various diagrams of human controlled vehicle yet they have a couple issues related to Fuel usage, riding capacities, human comfort, quality, and more drag force. This requires the change of EMT, dealing with a segment of the issues in existing. This envisions relies on upon making a pedal work electric human exertion vehicle. [1]

\section{Objective of Fabrication}

The significant targets and related work plan to satisfy these can be extensively compressed as:

- To dispense with fuel.

- To run a vehicle by rhythm at expressway speeds with the motor.

- To created electric vitality by influence component

- To keep away from consistent accelerating

- To lessen the heaviness of the vehicle.

- To update the style of the vehicle.

- To build up a proficient vitality stockpiling framework.

\section{Part Assemblies}

In sequence of practical development of Hybrid EMT, some part congregations required as takes after.

1. Frame Construction

2. Wheels and Tires

3. Suspension Arrangement

4. Steering Arrangement

5. Brakes

6. Energy Saving System

7. EMT Drive Arrangement

8. Body Cover Arrangement 


\section{Various Sub System of Electromechanical Tricycle}

A part congregation of a tricycle incorporates its casing or case, steering, brake, suspension, power train, distinctive safety hardware and other accessories.

\section{Frame Construction}

The configuration and advancement procedure of the roll confine includes different elements; specifically material choice, outline plan, cross-area determination. They included expected transmission, steering and suspension systems and their course of action, mounting of seat, layout components and gathering methodologies. It is in like manner required to keep sufficient freedom between the driver and the move bind part for the prosperity reason. This is done by giving bends instead of welds which in this manner lessen the costs. Every one of the estimations, for instance, seat position from back individuals, foot pedals, rooftop individuals with adequate head freedom, side effect individuals are controlled by setting the driver in the driving position. Additionally by thinking about the motor, drive train and batteries, the move pen is outlined. The front of the move enclosure is made by assuming control over the coordinating system and suspension gathering. Furthermore, individuals are given to mount the suspension and the wheels.

\section{Wheels And Tires}

Wheels are in charge of supporting the Hybrid EMT, exchanging energy to the asphalt, and keeping the rider in a turn when fundamental. Detectably, the most widely recognized type of the wheel for a Hybrid EMT is the spoke bike wheel. This is on the grounds that these wheels are intended to convey loads identical to a cyclist and rigging while keeping up a low weight

\section{Suspension}

Suspension structures of Hybrid EMT fill a twofold need adding to the vehicle's road holding/taking care of and braking for good element security and driving joy, and keeping Hybrid EMT occupants pleasing and sensibly particularly isolated from road upheaval, bumps, and vibrations. The suspension also guarantees the vehicle itself and any heap or things from harm and wear. Suspension is the course of action of springs, protections and linkages that interfaces a vehicle to its haggles relative development between these two.

\section{Steering}

Steering is the aggregation of sections, linkages so forth which allow a Hybrid EMT to take after the craved course. The central purpose of controlling is to ensure that the wheels are showing in the pined for direction. This is regularly proficient by a movement of linkages, shafts, turns and adjusts. One of the critical thoughts is that of caster edge - each wheel is guided with a turn point before the wheel; this makes the controlling have a tendency to act naturally focusing towards the course of travel.

\section{Brakes}

A brake is a mechanical device which quells development, decreasing or stopping a moving item or keeps its development. The key reason for fitting brakes on a vehicle is as underneath: In emergencies to pass on the vehicle to rest in the briefest conceivable separation. To control the vehicle when it is plunging along the slopes. To keep the vehicle in the pined for (sought) positions subsequent to getting it complete rest when there is no driver.

\section{Energy Saving System}

Under regenerative braking mechanism in Hybrid EMT has two small dynamo generators mounted on the free wheel makes a small current of power that holds your back safety light lit absent. In the blink of an eye expect you could run this system in converse. Think about how possible it is that you ousted the light and supplanted it with a vast battery. The battery would kick out a faithful electric present, driving the dynamo in inverse spun around of direction of wheel. As the dynamo work, it would attempt to oppose the tire movement and make the bike arrive at prevent and no help from your accelerating. [3]

\section{Emt Drive Arrangement}

The EMT driven by one driver. The EMT is controlled by both human and electric force. The driver can control the vehicle using a wrench or torque wheels as a part of the front portion of body. The general manual transmission has a 31 Speed Gear get together lastly picks an uncommon drive course of action of $32 \mathrm{~T}$ and $18 \mathrm{~T}$ chain sprocket plan. The electrical transmission of the EMT comprises of a DC motor. The DC motor is powered by a battery which is mounted in the Rear part of the body on back wheel.

\section{Body Cover Arrangement}

As per its utilization, environmental and streamlined, Hybrid EMT is presented to different climate sorts who cause wear and tear. Notwithstanding the dust and grime kept by nature, there is additionally the irritation of 
cleaning bug effects and feathered creature droppings. Branches or protests that can scratch or cause minor harm to a vehicle's body are another auto care nuisance.

\section{Orthographic Views and Isometric View}

Orthographic view contain elevation plan and profile view of Hybrid EMT and Isometric view shows three dimensional perspective of Hybrid EMT.

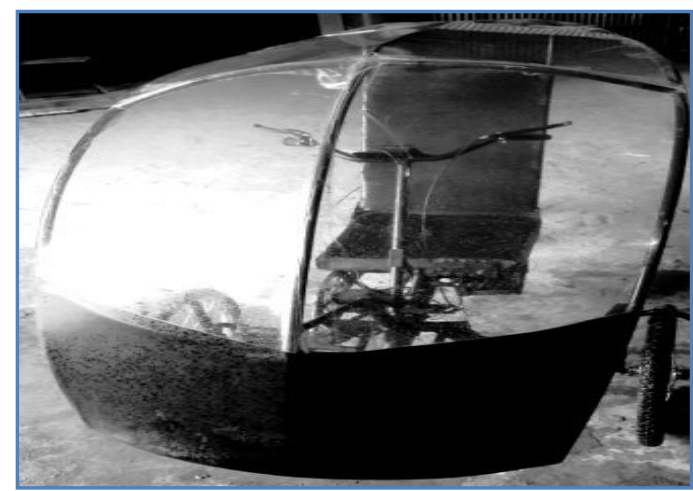

Fig. 1 Front View of Hybrid EMT

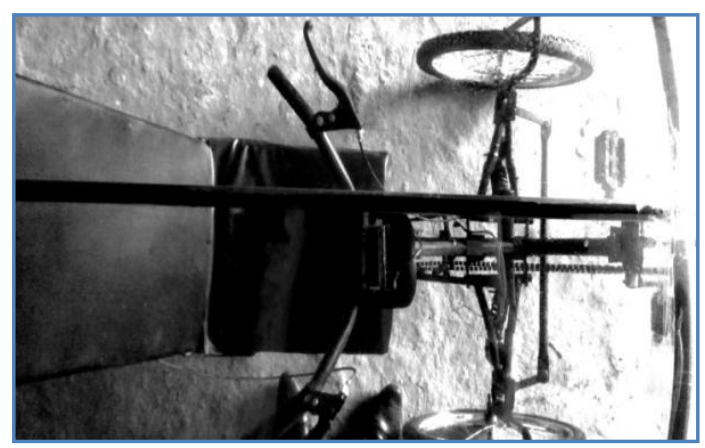

Fig. 2 Top View of Hybrid EMT

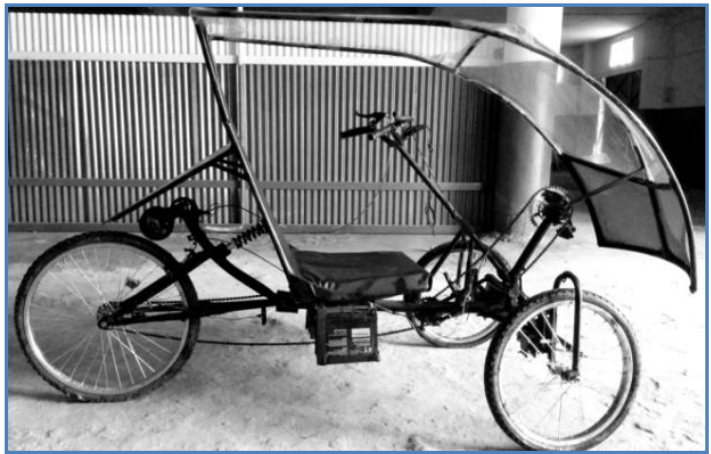

Fig. 3 Side View of Hybrid EMT

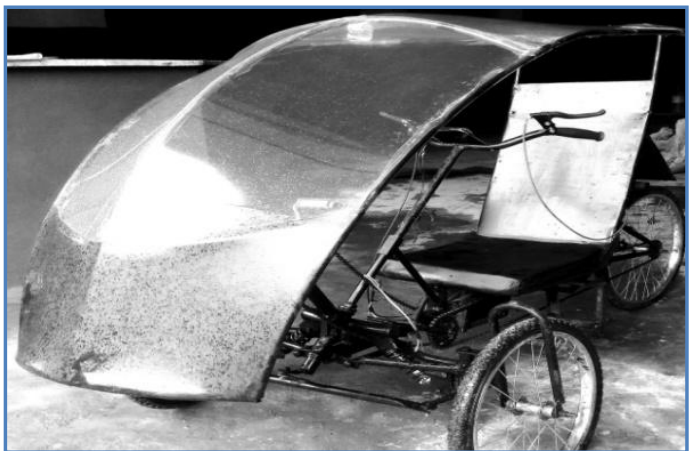

Fig. 4 Isometric View of Hybrid EMT 


\section{Conclusion}

By this anticipate study I attempt to gather those information and data which can be useful for building a Hybrid vehicle which is natural and in addition economical in the field of car. Presently days the best concern in the field of car is to build up those vehicles which are environment well disposed and can give a modest bunch measure of vitality to transport the things. I can see numerous undertaking worked far and wide just to grow such environment friendly machines. I am attempting to build up a machine which can keep running with the assistance of electric force and also human force, both types of vitality are eco-accommodating and effectively accessible. The auto world is changing bit by bit which characterizes an ascent of new period, a time which ruled by these Hybrid creatures. This anticipates is only a little inclusion in the creating of an economical eco-friendly vehicle which is in handle of each individual present on earth. I simply attempting to build up a less expensive however viable method for transport which helps an exceptional gathering of individuals who are unemployed and additionally confronting monetary issues. At last simply need to say that this anticipate is not only a task, it's a one stage forward towards the time of mixture vehicle, a period which is ruled and affected by the "Practice environmental awareness" idea and that is also our prime concern to build up a machine which satisfies the GO GREEN necessities.

\section{Refrences}

[1] Abhinay Nigam, Prof. Suman Sharma, Prof. Rupesh Tiwari, A Review Report on Electromechanical Tricycle with Regenerative Braking System 2015 IJSRSET | Volume 1 | Issue 6 | Print ISSN : 2395-1990 | Online ISSN : 2394-4099 Themed Section: Engineering and Technology

[2] Pedal at Highway Speeds with the RAHT Racer, RAHT Racer Kickstarter on 2/26/15, 11:44 PM

[3] In the tutorial of http://what-when-how.com/automobile/braking-system-automobile/

[4] Swarnim Shrishti, Anand Amrit, Design and Development of Hybrid Human Powered Vehicle, ethesis.nitrkl.ac.in/5892/1/110ID0275-11.pdf

[5] Richard 'Barney' Carlson, Matthew G. Shirk, and Benjamin M. Geller's Factors Affecting the Fuel Consumption of Plug-In Hybrid Electric Vehicles, EVS-25 Shenzhen, China, Nov. 5-9, 2010. The 25th World Battery, Hybrid and Fuel Cell Electric Vehicle Symposium \& Exhibition 